\title{
Properties of Trichomonas vaginalis grown under chemostat controlled growth conditions
}

\author{
Michael W Lehker, J F Alderete
}

\begin{abstract}
Trichomonas vaginalis isolates NYH 286 and IR 78 were grown in continuous flow culture conditions in a complex trypticase-yeast extract-maltose medium supplemented with heat-inactivated horse serum. Parasites could be stably maintained in the chemostat at high densities ranging from $1 \times 10^{6}$ to $1 \times 10^{7}$ organisms $\mathrm{ml}^{-1}$. Growth densities, acid production, and profiles of total versus secreted trichomonad proteins were characterised at different rates of growth and pH. Growth rate influenced the extent of parasite production of acid and the shedding of proteins into the medium but had no effect on overall parasite density. Lowering the pH from 6.0 to 5.0 resulted both in a decrease of cell density and acid production. At pH 4.5 isolate IR 78 but not NYH 286 was capable of growth and multiplication, showing the ability of some isolates to survive at the vaginal pH of healthy individuals. At this lower pH, however, isolate NYH 286 but not IR 78 synthesised new proteins which were detectable in stained gels. Also, inoculation of the chemostat with isolate NYH 286 comprising a mixture of fluorescent (positive, pos) and nonfluorescent (negative, neg) trichomonads as defined by monoclonal antibody reactivity to a surface immunogen resulted in a change in the parasite population to an almost homogeneous neg phenotype. These neg phenotype organisms switched back to pos phenotype after transfer to test tubes.
\end{abstract}

Trichomonas vaginalis is a sexually transmitted flagellated protozoan of the human urogenital tract. Trichomoniasis in women ranges from an asymptomatic, carrier state to intense inflammation of the vaginal epithelium, which can be accompanied by itching, a purulent, white discharge, and severe abdominal pain. ${ }^{12}$ Usually the infection in women is non-self-limiting, causing extensive morbidity.

Department of Microbiology, The University of Texas Health Science Center, San Antonio, TX, USA M W Lehker, J F Alderete
Possible virulence factors of $T$ vaginalis include antigenic heterogeneity, ${ }^{2}$ phenotypic variation, ${ }^{3}$ haemolysis, ${ }^{4}$ cytadherence, ${ }^{56}$ cytotoxicity ${ }^{78}$ proteinases, ${ }^{9}$ and secretion of immunogens into the culture medium..$^{10}$ The host environment may also influence or determine the extent of parasite virulence and disease pathogenesis. For example, host factors in the vagina including menstrual blood, ${ }^{11}$ hormonal levels, ${ }^{12}$ extent of inflammation, ${ }^{13}$ normal flora, ${ }^{2}$ oxygen tension, ${ }^{14}$ and nutrient availability ${ }^{15-17}$ can all contribute to the nature and extent of infection. Indeed the ability of complement in menstrual blood to kill trichomonads has been demonstrated, ${ }^{11} 18$ and subpopulations of $T$ vaginalis organisms refractory to the lysis by complement ${ }^{11}$ represent surviving parasites with possibly a unique antigenic profile now present in the host.

Nutritional limitations, along with other related parameters such as slow growth rates and $\mathrm{pH}$, as might be encountered in the host, can be examined through the use of a chemostat. ${ }^{19}$ For this reason continuous flow culture might be useful for studying physiologic parameters that lead to expression of factors involved in establishment and maintenance of $T$ vaginalis infection. In this paper we report on the growth of $T$ vaginalis in a chemostat fermentor system. Trichomonads could be stably maintained for prolonged periods of time. Growth rate and $\mathrm{pH}$ were found to affect cell density and secretion of proteins into the medium. When compared with test tube grown trichomonads, major differences in total protein profiles were detected. In addition, isolates

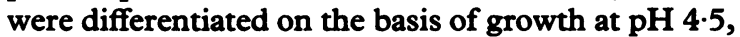
the normal vaginal $\mathrm{pH}$.

Materials and methods MEDIA AND GROWTH

$T$ vaginalis isolates NYH 286 and IR 78 have been described elsewhere, ${ }^{320-22}$ and were grown in trypticase-yeast extract-maltose (TYM) medium supplemented with $10 \%$ heat-inactivated horse serum ${ }^{23}$ throughout this study. Late logarithmic-phase organisms ${ }^{24}$ were then inoculated directly into the growth vessel containing TYM-serum medium to achieve an initial density of $1 \times 10^{5} \mathrm{org} \mathrm{m}^{-1}$. Trichomonads were then grown aerobically at $37^{\circ} \mathrm{C}$ at dilution rates of 0.07 hour $^{-1}(\mathrm{~h}), 0.013 \mathrm{~h}^{-1}$ and 0.007 $h^{-1}$ which gave doubling times $\left(t_{d}\right)$ of $10 h, 50 h$ and 
$100 \mathrm{~h}$, respectively. The $t_{d} s$ were calculated based on flow rates of TYM-serum medium added to the culture vessel. ${ }^{25}$ For each analysis the chemostat was allowed to equilibrate by passing at least four complete changes of TYM-serum medium through the vessel. Culture $\mathrm{pH}$ was maintained automatically at pH $6.0,5.0$ or 4.5 with sterile $5 \mathrm{~N} \mathrm{NaOH}$ or $5 \mathrm{~N} \mathrm{HCl}$ and continuously monitored with an autoclavable $\mathrm{pH}$ electrode. Cells were enumerated microscopically with an improved Neubauer haemocytometer. Data obtained are the average of triplicate determinations of no less than two independent experiments.

\section{INDIRECT IMMUNOFLUORESCENCE}

Preparation of trichomonads for indirect immunofluorescence for detection of surface expressed immunogens was identical to a previously described procedure. ${ }^{321} 22 \mathrm{~A}$ monoclonal antibody (MAb) designated $\mathrm{C} 20 \mathrm{~A} 3$ was used to differentiate fluorescent (pos phenotype) from nonfluorescent (neg phenotype) subpopulations of isolate NYH 286. Isolate IR 78 synthesises but does not express the immunogen on the surface ${ }^{3}$ and consists of homogeneous, stable neg phenotype trichomonads as defined by this $M A b .{ }^{32}$

SODIUM DODECYL SULFATE (SDS)-POLYACRYLAMIDE GEL ELECTROPHORESIS (PAGE) AND IMMUNOBLOT

The preparation of total trichloroacetic acidprecipitated proteins was done as previously detailed. ${ }^{20}$ SDS-PAGE was also performed as described before using 3\% stacking and $7.5 \%$ separating acrylamide gels. ${ }^{20}$ Low and high molecular weight protein markers were purchased from BioRad Labs, Richmond, CA. Electrophoretic transfer of trichomonad proteins from acrylamide gels was also performed as before. ${ }^{3}$ Nitrocellulose blots were then blocked with $5 \%$ nonfat dry milk in TBS (Tris, 20 $\mathrm{mM} ; \mathrm{NaCl}, 500 \mathrm{mM} ; \mathrm{pH} 7.5)$ for $2 \mathrm{~h}$ at room temperature (RT). Rabbit anti-NYH 286 or IR 78 serum $^{20}$ diluted $1: 500$ in $5 \%$ milk-TBS was then added and incubated overnight at $4^{\circ} \mathrm{C}$. These antisera did not react with any culture medium components. The blots were then washed three times with TBS at RT. Goat anti-rabbit immunoglobulin conjugated to horseradish peroxidase (BioRad Labs) was added to a final dilution of 1:2000. The blots were incubated at RT for $4 \mathrm{~h}$, washed three times for 15 minutes ( $\mathrm{min}$ ) with TBS, and developed with TBS containing 4-chloro-1-naphtol $\left(2 \mathrm{mg} \mathrm{m}^{-1}\right), 20 \%$ methanol and $0.015 \% \mathrm{H}_{2} \mathrm{O}_{2}$.

\section{PREPARATION OF PARASITE ANTIGENS PRESENT IN CULTURE SUPERNATANTS}

Trichomonads harvested from the chemostat were removed from the medium by centrifugation at $500 \times g$ at $4^{\circ} \mathrm{C}$ for $15 \mathrm{~min}$. Supernatant was carefully decanted without disturbing the cell pellet and centrifuged at $20,000 \times g$ at $4^{\circ} \mathrm{C}$ for $10 \mathrm{~min}$. Calcified supernatant was then filtered through a $0.45 \mu \mathrm{m}$ Gelman aerodisk (Gelman Science Inc., Ann Arbor, MI) to remove any additional insoluble material. Supernatants were stored at $-70^{\circ} \mathrm{C}$ until used. For SDS-PAGE the samples were combined with an equal volume of twofold concentrated dissolving buffer. ${ }^{20}$ Volumes loaded onto gels were approximately $30 \mu \mathrm{l}$ and corresponded to $2 \times 10^{4}$ organisms. As a control to monitor whether lysis of parasites accounted for the protein bands observed,

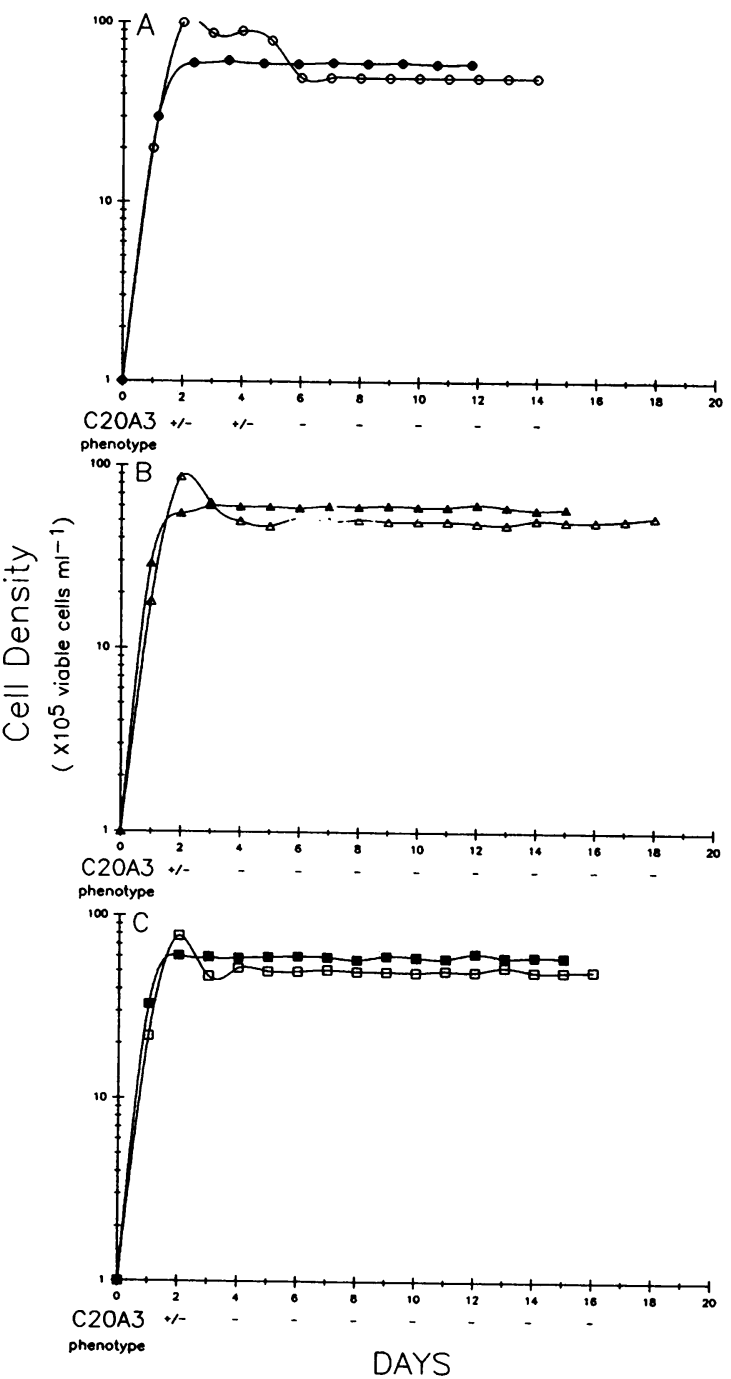

Figure 1 Growth of T vaginalis isolates $N Y H 286(O, \triangle$, $\square)$ and $I R 78(O, \Delta, \square)$ in a chemostat at generation times of $10 \mathrm{~h}(\mathrm{~A}), 50 \mathrm{~h}(\mathrm{~B})$ and $100 \mathrm{~h}(\mathrm{C})$. The C20A3 phenotype refers to that of isolate NYH 286 and was determined by indirect immunofluorescent with monoclonal antibody C20A3 as described in Materials and methods. Each point represents the average of three independent determinations. 


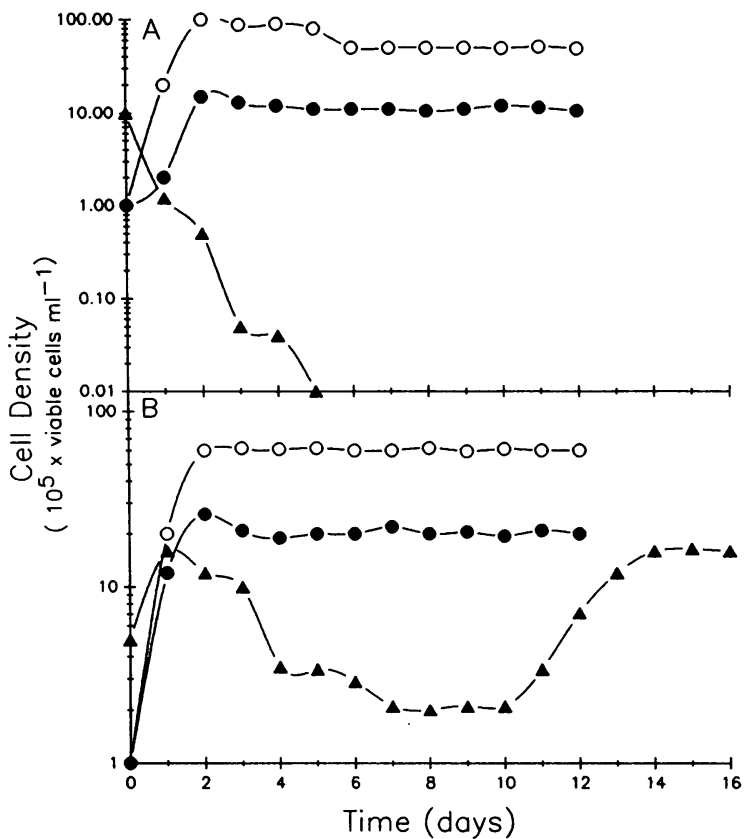

Figure 2 Growth characteristic of $T$ vaginalis isolated NYH 286 (panel $A$ ) and IR 78 (panel $B$ ) in a chemostate

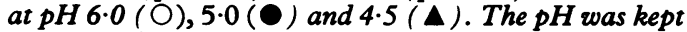
constant with an automatic $p H$ control module by the addition of $5 \mathrm{~N} \mathrm{NaOH}$.

an immunoblot was also done using total proteins from $2 \times 10^{4}$ trichomonads. This amount of trichomonad proteins failed to give any bands, consistent with earlier findings by us. ${ }^{10}$

\section{Results}

GROWTH OF $T$ VAGINALIS ISOLATES NYH 286 AND IR 78 AT VARIOUS DILUTION RATES AND $\mathrm{pH}$

Steady state growth for both isolates was achieved when parasite density as shown in fig 1 and 2 and acid production as presented in the table remained constant for each growth rate. Levels of cell densities of chemostat grown organisms ranged from $1 \times 10^{6}$ to $5 \times 10^{6}$ org $\mathrm{ml}^{-1}$ and compared favourably with previous reports by us on densities of trichomonads from batch cultures. ${ }^{24}$

We next wanted to determine whether this pathogenic protozoan could be grown at different generation times $\left(t_{d} s\right)$. Compared with batch cultures where triochomonads have a $t_{d}$ of $4-6 h,{ }^{24} T$ vaginalis in chemostat cultures had $t_{d} s$ of up to $150 \mathrm{~h}$. As shown in fig 1 , different experiments were performed and parasite densities were unaffected by $t_{d} s$ of 10 (part A), 50 (part B) and $100 \mathrm{~h}$ (part C) for either $T$ vaginalis isoiates NYH 286 or IR 78.

Lowering the $\mathrm{pH}$ from 6.0 to 5.0 , however, resulted in a five-fold and three-fold decrease in cell density for isolates NYH 286 (fig 2A) and IR 78 (fig
2B), respectively. No multiplication of $T$ vaginalis NYH 286 organisms was detectable at $\mathrm{pH} 4 \cdot 5$, and this resulted in parasite dilution due to removal of parasites from the growth vessel (fig 2A). Isolate NYH 286 also could not grow at $\mathrm{pH} 4.5$ in batch cultures. In contrast, isolate IR 78 reached a cell density of $1.6 \times 10^{6} \mathrm{org} \mathrm{ml}^{-1}$ followed by a decrease to $2 \times 10^{5}$ org ml ${ }^{-1}$ at $\mathrm{pH} 4.5$ (fig 2B). This cell number remained stable for four days followed by an increase to $1.6 \times 10^{6} \mathrm{org} \mathrm{ml}^{-1}$ by day 14 , indicating growth and multiplication at $\mathrm{pH} \mathrm{4.5}$. Isolate IR 78 could also grow in batch culture at $\mathrm{pH} 4.5$ and reached a density of $5 \times 10^{5} \mathrm{org} \mathrm{ml}^{-1}$. These results clearly differentiate $T$ vaginalis isolates on the basis of their ability to survive at the normal vaginal $\mathrm{pH}$.

\section{ACID PRODUCTION}

Batch culture pH decreases from 6.2 to 4.5 during growth of $T$ vaginalis. ${ }^{24}$ To establish if acid production is dependent on growth rate and medium $\mathrm{pH}$, the consumption of $\mathrm{NaOH}$ to maintain a stable $\mathrm{pH}$ in the chemostat growth vessel was measured. Acid production declined when the generation time increased due to nutrient limitation or when the growth $\mathrm{pH}$ was decreased (table). The amount of acid produced was always higher for isolate IR 78 than NYH 286, and only isolate IR 78 produced acid at pH 4.5 (table).

\section{PHENOTYPIC VARIATION}

We also wanted to determine whether phenotypic variation for the expression of immunogens occurred in chemostat cultures as has been shown for batchgrown organisms. ${ }^{322627}$ A heterogeneous population was used to seed the culture vessel, and the parasites were monitored daily by indirect immunofluorescence using antibody. A shift of the parent heterogenous ( $30 \%$ pos phenotype) population to neg phenotype was always observed regardless of the culture $t_{d}$ (fig 1). At no time were greater than $1 \%$ trichomonads fluorescent during the remainder of the experiment. The dramatic shift of the parent NYH 286 population to an almost homogeneous neg

Table The effect of various growth conditions on the amount of acid produced by T vaginalis NYH 286 and IR 78.

\begin{tabular}{|c|c|c|c|}
\hline \multirow[b]{2}{*}{ Generation time } & \multirow[b]{2}{*}{ Medium $p H$} & \multicolumn{2}{|c|}{ Acid produced fmol $\left(h^{-1}\right.$ org $\left.^{-1}\right) \star$} \\
\hline & & $\begin{array}{l}\text { isolate: } \\
\text { NYH } 286\end{array}$ & IR 78 \\
\hline $\begin{array}{r}10 \\
50 \\
\geqslant 100 \\
50 \\
50\end{array}$ & $\begin{array}{l}6.0 \\
6.0 \\
6.0 \\
5.0 \\
4.5\end{array}$ & $\begin{array}{c}170 \cdot 0 \text { SD } 21 \cdot 0 \\
84.0 \text { SD } 18.0 \\
\mathrm{~nm}^{\dagger} \\
5 \cdot 4 \text { SD } 3.0 \\
\mathrm{~nm}\end{array}$ & $\begin{array}{r}580 \text { SD } 52 \cdot 0 \\
270 \text { SD } 33 \cdot 0 \\
\text { nm } \\
140 \text { SD } 17 \cdot 0 \\
80 \text { SD } 24 \cdot 0\end{array}$ \\
\hline
\end{tabular}

*average of triplicate determinations done on three different experiments.

tnm, not measurable. 


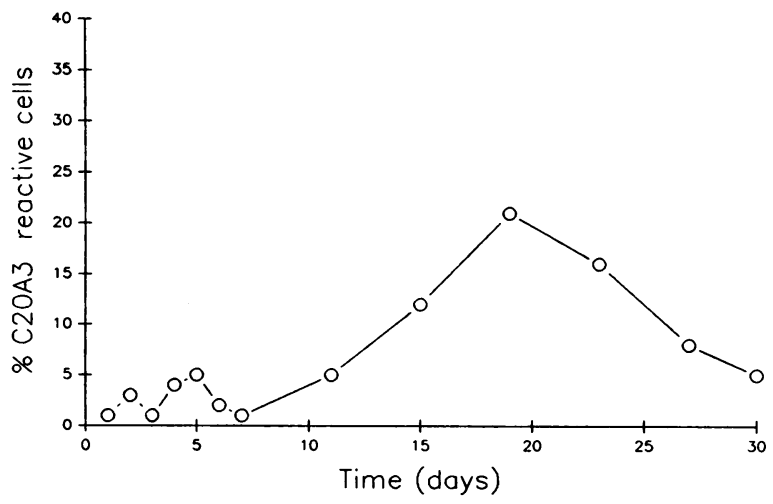

Figure 3 Reversion of T vaginalis NYH 286 to a heterogeneous phenotype after transfer of a homogenous neg phenotype grown in a chemostat to test tube culture. The phenotype was determined by indirect inmmunofluorescence with monoclonal antibody C20A3. Each point represents three independent determinations of at least 100 organisms counted from at least ten different fields.

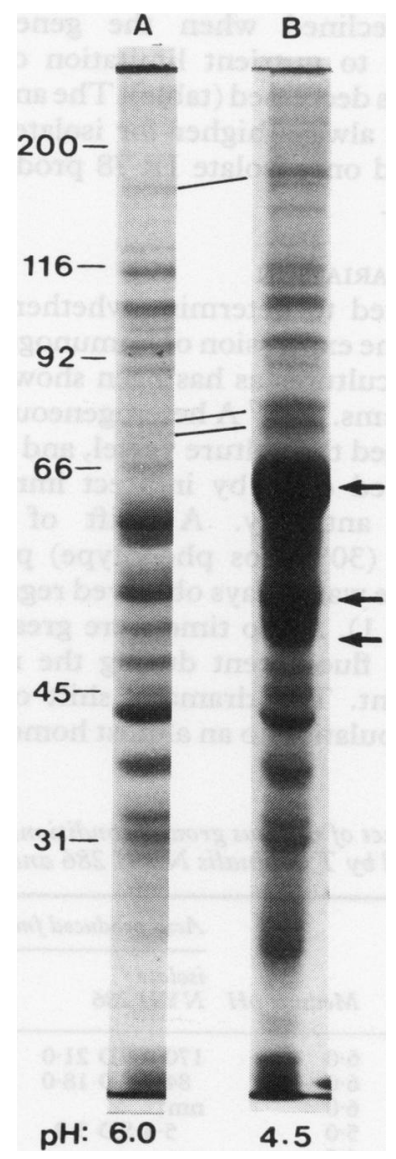

Figure 4 SDS-PAGE of total trichloroacetic acidprecipitated proteins of T vaginalis NYH 286 grown in a chemostat at pH 6 (lane $A$ ) or pH 4.5 (lane B).

phenotype was demonstrated during six independent experiments where the parent populations were comprised of different percentages $(30 \%$ to $50 \%$ ) of pos phenotype organisms.

Neg phenotype organisms were then removed from the chemostat at different times and propagated daily in test tubes. Figure 3 shows representative data of almost homogeneous neg phenotype parasites reverting to the pos phenotype. Clearly, chemostat conditions favoured the lack of surface expression of a prominent immunogen but did not select for a stable neg phenotype. As expected, isolate IR 78 remained neg phenotype throughout. ${ }^{3}$

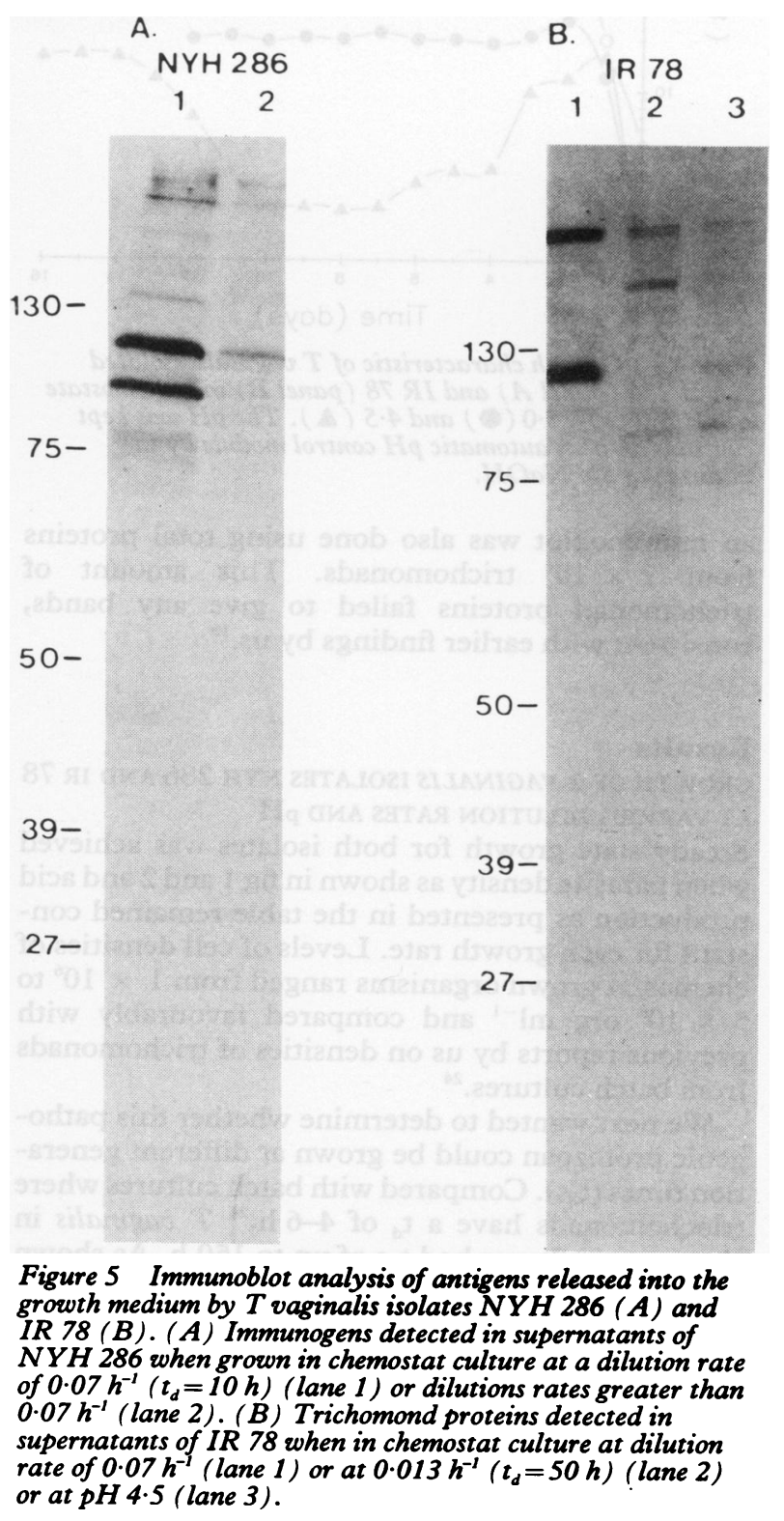


SDS-PAGE AND IMMUNOBLOT OF TOTAL AND SECRETED PROTEIN

Qualitative and quantitative variation among certain proteins was apparent and reproducible when comparing gel profiles of isolate NYH 286 grown in the chemostat at different $\mathrm{pH}$ values. For example, SDSPAGE of total trichloroacetic acid precipitated proteins from the same number of organisms ${ }^{20}$ revealed dramatic differences in the protein profiles at $\mathrm{pH} \mathrm{4.5}$ (fig 4, lane $\mathrm{B}$ ). The protein pattern of trichomonads at $\mathrm{pH} 6.0$ was identical to that previously determined for batch-grown parasites. ${ }^{20}$ Similar dramatic differences in protein patterns were not seen for isolate IR 78 at these pHs.

The possibility that chemostat growth conditions influenced the release of proteins into the medium was also investigated. At all variables examined for both batch and chemostat cultures of NYH 286 (fig 5A), high $\mathrm{Mr}$ protein immunogens (>70-kDa) appeared to predominate in supernatants. Two intense bands of proteins of $\sim 130-\mathrm{kDa}$ were secreted into the growth medium only at a $t_{d}$ of $10 \mathrm{~h}$ (fig $5 \mathrm{~A}$, lane 1). Much less secretion of immunogens appeared to occur when organisms were grown with $t_{d} s>10 \mathrm{~h}$ (lane 2). Finally, immunoblot using total proteins from $2 \times 10^{4}$ trichomonads, the equivalent cell number of supernatant used in these experiments, did not give any bands under the same conditions. These data show the selective enrichment for these immunogens in culture supernatants.

For isolate IR 78, two immunoblot patterns were observed of antigens released into the chemostat growth medium. The first pattern from chemostat cultures at a $t_{d}$ of $10 \mathrm{~h}$ at $\mathrm{pH} 6.0$ consisted of two prominent high molecular weight immunogens ( $>110-\mathrm{kDa}$ ) (fig 5B, lane 1). Another pattern was observed for parasites grown at a $t_{d}$ of $50 \mathrm{~h}$ at $\mathrm{pH} 6.0$ and indicated the release of several antigens ranging in molecular weight from $75-\mathrm{kDa}$ to $200-\mathrm{kDa}$ (lane 2). $T$ vaginalis grown at a $t_{d}$ of $50 \mathrm{~h}$ but at $\mathrm{pH} 4.5$ gave a pattern similar to that seen with organisms grown at

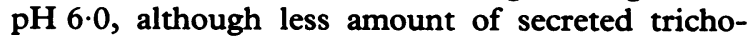
monad protein was seen (fig $5 B$, lane 3 ). Both isolates NYH 286 (fig 5A) and isolate IR 78 (fig 5B) demonstrated decreased secretion at longer $t_{d} s$.

\section{Discussion}

This study showed that $T$ vaginalis can be grown successfully in a controlled chemostat system. High cell densities were achieved in the chemostat under various growth rates and $\mathrm{pH}$ as has been reported for test-tube grown cultures. ${ }^{24}$ The generation times of chemostat trichomonads were much greater than those reported for batch cultures, which ranged from four to six hours. ${ }^{24}$ For example, in the chemostat we were able to demonstrate a generation time for $T$ vaginalis of up to $150 \mathrm{~h}$. The in vivo generation time for this pathogen is unknown, but the doubling time might be expected to be considerably higher due to nutrient limitation and other factors in the vagina. This ability of the parasite to have long generation times as seen here may very well be relevant to the non-self-limiting nature of trichomoniasis.

The decrease in cell number for $T$ vaginalis isolate NYH 286 grown at pH 4.5 in the chemostat (fig 2) indicates an adverse effect of $\mathrm{pH}$ on overall parasite physiology. This is consistent with known effects of $\mathrm{pH}$ on amount and extent of enzymatic activity and energy generation for other microorganisms. ${ }^{28-30}$ Interestingly, isolate NYH 286 also produced dramatically less acid (table) than IR 78 at all generation times and medium pHs studied. Since lactate may be the major acid product of $T$ vaginalis metabolism, ${ }^{231}$ it is likely that a low $\mathrm{pH}$ provides a signal for decreasing acid production, which in turn results in decreased ATP generation. This then would be consistent with the observed diminished growth and elevated generation time for isolates like NYH 286. On the other hand isolate IR 78 appears more acid tolerant, as evidenced by the increase in cell density at $\mathrm{pH} 4.5$ (fig $2 \mathrm{~B}$ ), and this suggests that low $\mathrm{pH}$ may not provide signalling to allow for the extent of decreased growth and higher generation times similar to NYH 286. These data may be meaningful to the in vivo situation, since isolates like NYH 286 are known to cytadhere optimally at elevated $\mathrm{pH}$ values ( $\mathrm{pH} 5.5$ to $\mathrm{pH} \mathrm{6.0).}{ }^{5}$ Some isolates like IR 78 may be at an advantage compared to other isolates in cases where the $\mathrm{pH}$ in patients remains low $(\mathrm{pH} \sim 4 \cdot 5) .^{232}$

Another finding of this study was that phenotypic variation of a major immunogen which occurs in batch cultures ${ }^{23}$ was suppressed in organisms grown in the chemostat (fig 1). This observation was also documented for other isolates as well, including JH31A and AL20W, which are also heterogeneous for surface immunogens. ${ }^{22}$ The fact that most fresh isolates from patients are negative for surface expression of this and other immunogens, ${ }^{27}$ which correlates with increased virulence properties, ${ }^{22}$ perhaps indicates that key selective pressures in vivo may in fact involve severe nutrient limitation leading to very extended generation times as shown here.

This study also shows that the overall protein composition of trichomonads may be influenced by environmental changes like $\mathrm{pH}$ and specific growth rate (fig 4). It is noteworthy that protein patterns of chemostat organisms at $\mathrm{pH} 6.0$ were similar to previously published profiles of test tube parasites, ${ }^{2021}$ but dramatic qualitative and quantitative differences were observed in proteins of trichomonads of isolate NYH 286 grown in the chemostat at low $\mathrm{pH}$ (fig 5 ). The $\mathrm{pH} 4.5$ protein pattern may actually be demonstrating a parasite response to stress resulting from the vaginal $\mathrm{pH}$ (fig 5, lane $B$ ), and this may be consistent with the 
inability of this isolate to grow at this $\mathrm{pH}$ (fig 2). Isolates like IR 78 which do not give an altered protein pattern at $\mathrm{pH} 4.5$ as do isolates like NYH 286 may represent parasites capable of growth under these conditions (fig 2). These results illustrate the importance of growth conditions on possible enhanced or new expression of immunogens, and it will be important to analyse these organisms grown under in vivo-like conditions in the chemostat for certain virulence properties. This is especially important, since researchers have utilised only test-tube grown organisms for studies involving antigen analysis, $^{2391027}$ antibody production, ${ }^{321}$ and virulence. ${ }^{4822}$

Shedding of antigens also appeared to be influenced by medium $\mathrm{pH}$ and $T$ vaginalis growth rate (fig 5). Contrary to an earlier study of batch cultures which showed the release of many proteins ranging from $30-k D a$ to $300-k D a$ into the culture medium, ${ }^{10}$ only few high molecular weight immunogens ( $>70 \mathrm{kDa}$ ) were shed by chemostat-grown organisms (fig 5). Although these experiments may be crucial for identifying selectively secreted or released proteins by $T$ vaginalis, these results along with the ability of $T$ vaginalis to have long generation times may indicate that soluble parasite immunogens may not be as common in the vagina as suggested earlier. ${ }^{10}$

Overall, continuous culture provides the most controlled method for growth of $T$ vaginalis. This paper represents the foundation for our continued goal of understanding external signals which may be involved in expression of virulence factors for the pathogenic human trichomonads. It would appear that the effects of environmental changes on growth, product formation, and expression of virulence factors as reported for other microbial pathogens ${ }^{33-35}$ can now be performed for this important sexually transmitted parasite.

This study was supported by Public Health Service grant AI-22380 from the National Institutes of Allergy and Infectious Diseases, National Institutes of Health. The excellent secretarial assistance of Diana Hinojosa and Pat Hart is especially acknowledged.

Address for reprints: Dr John F Alderete, Department of Microbiology, The University of Texas Health Science Center, 7703 Floyd Curl Drive, San Antonio, TX 78284-7758, USA.

1 Müller M. Trichomonas vaginalis and other sexually transmitted protozoan infections. In: Holmes KK, Mardh P, eds. International Perspectives of Neglected Sexually Transmitted Disease, New York: Hemisphere Publishing Corp 1983:113-24.

2 Honigberg BM. Trichomonads of importance in human medicine. In: Kreier JP, ed. Parasitic Protozoa, Vol 2, New
York: Academic Press, Inc. 1978:275-454.

3 Alderete JF, Suprun-Brown L, Kasmala L. Monoclonal antibody to a major surface glycoprotein immunogen differentiates isolates and subpopulations of Trichomonas vaginalis. Infect Immun 1986;52:70-5.

4 Krieger JN, Poisson MA, Rein MF. Beta-hemolytic activity of Trichomonas vaginalis correlates with virulence. Infect Immun 1983;41:1291-5.

5 Alderete JF, Garza GE. Specific nature of Trichomonas vaginalis parasitism of host cell surfaces. Infect Immun 1985;50:701-8.

6 Krieger JN, Ravidin JI, Rein MF. Contact-dependent cytopathogenic mechamisms of Trichomonas vaginalis. Infect Immun 1985;50:778-86.

7 Alderete JF, Pearlman E. Pathogenic Trichomonas vaginalis cytotoxicity to cell culture monolayers. $\mathrm{Br} J$ Venereal Dis 1984;60:99-105.

8 Kulda J, Honigberg BM. Behavior and pathogenicity of Trichomonas vaginalis in chick liver cell cultures. J Protozool 1969;16:479-95.

9 Lockwood BC, North MJ, Scott KI, Bremner AF, Coombs GH. The use of a highly sensitive electrophoretic method to compare the proteinases of trichonomads. Mol Biochem Parasitol 1987;24:89-95.

10 Alderete JF, Garza GE. Soluble Trichomonas vaginalis antigens in cell-free culture supernatants. Mol Biochem Parasitol 1984;13:147-58.

11 Demeš $P$, Gombošová $A$, Valent $M$, Janošov̌a $H$, Fabušov́a $H$, Petrenko M. Differential susceptibility of fresh Trichomonas vaginalis isolates to complement in menstrual blood and cervical mucus. Genitourin Med 1988;64:176-9.

12 Sugarman B, Mummaw N. The effect of hormones on Trichomonas vaginalis. J Gen Microbiol 1988;134:1623-8.

13 Bein MF, Sullivan JA, Mandell GL. Trichomonacidal activity of human polymorphonuclear neutrophils; killing by disruption and fragmentation. $J$ Infect Dis 1980;142:575-85.

14 Yarlett N, Yarlett NC, Lloyd DC. Metronidazole-resistant clinical isolates of Trichomonas vaginalis have lowered oxygen affinities. Mol Biochem Parasitol 1986;19:111-6.

15 Gorrell TE. Effect of culture medium iron content on the biochemical composition and metabolism of Trichomonas vaginalis. J Bacteriol 1985;161:1228-30.

16 Peterson KM, Alderete JF. Iron uptake and increased intracellular enzyme activity follow host lactoferrin binding by Trichomonas vaginalis receptors. J Exp Med 1984;106: 398-410.

17 Peterson KM, Alderete JF. Trichomonas vaginalis is dependent on uptake and degradation of human low density lipoproteins. $J$ Exp Med 1984;160:1261-72.

18 Gillin FD, Sher AC. Activation of the alternative complement pathway by Trichomonas vaginalis. Infect Immun 1981;34: 268-73.

19 Roth M, Noak DC. Genetic stability of differentiated functions in Streptomyces hydroscopicus in relation to conditions of continuous culture. J Gen Microbiol 1982;128:107-14.

20 Alderete JF. Antigen analysis of several pathogenic strains of Trichomonas vaginalis. Infect Immun 1983;39:1041-7.

21 Alderete JF. Identification of immunogenic and antibodybinding membrane proteins of pathogenic Trichomonas vaginalis. Infect Immun 1983;40:284-91.

22 Alderete JF, Kasmala L, Metcalfe E, Garza GE. Phenotypic variation and diversity among Trichomonas vaginalis isolates and correlation of phenotype with trichomonal virulence determinants. Infect Immun 1986;53:285-93.

23 Diamond LS. The establishment of various trichomonads of animals and man in axenic cultures. $J$ Parasitol 1957;43: 488-90.

24 Petersen KM, Alderete JF. Host plasma proteins on the surface of pathogemic Trichomonas vaginalis. Infect Immun 1982;37:755-62.

25 Tempest $\mathrm{DW}$. The continuous cultivation of micro-organisms: 1. Theory of the chemostat. In: Norris JR, Ribbons DW, eds Methods in Microbiology, London: Academic Press 1970: 259-76.

26 Alderete JF. Trichomonas vaginalis NYH 286 phenotypic variation may be coordinated for a repertoire of trichomonad surface immunogens. Infect Immun 1987;55:1957-62.

27 Alderete JF, Demeš P, Gombošová A, Janoška A, Fabušová $H$, Kasmala L, Garza GE, Metcalfe EC. Phenotypes and proteinepitope phenotypic variation among fresh isolates of Trichomonas vaginalis. Infect Immun 1987;55:1037-41.

28 Gale EF, Epps HMR. The influence of the presence of glucose during growth on the enzymatic activities of Escherichi coli: 
comparison of the effect with that produced by fermentation acids. Biochem J 1942;36:619-23.

29 Blackwood AC, Neish AC, Ledingham T. Dissimilation of fucose at controlled $\mathrm{pH}$ values by pigmented and non-pigmented strains of Escherichia coli. J Bacteriol 1956;72:489-97.

30 Hernandez E, Johnson MJ. Anaerobic growth yields of Aerobacter cloacae and Escherichia coli. J Bacteriol 1967;94:991-5.

31 Müller M. Energy metabolism of protozoa without mitochondria. Annual review of Microbiology 1988;42:465-88.

32 Yarlett $\mathrm{N}$. Polyamine biosynthesis and inhibition in Trichomonas vaginalis. Parasitology Today 1988;4:357-60.

33 Keevil CW, Major NC, Davies DB, Robinson A. Physiology and virulence determinants of Neisseria gonnorrhea grown in glucose-. oxygen- or cystine-limited continuous culture. JGen Microbiol 1986;132:3289-302.

34 Jacques NJ, Morrey-Jones JG, Walker GW. Inducible and constitutive formation of fructanase in batch and continuous cultures of Streptococcus mutans. J Gen Microbiol 1985;131:1625-33.

35 Cove JH, Holland KT, Cunliffe WJ. Effects of oxygen concentration on biomass production, maximum growth rate and extracellular enzyme production by three species of cutaneous propionibacteria grown in continuous culture. J Gen Microbiol 1983;129:3327-34. 